\title{
A Simplified Approach for the Prioritization of Bridge Stock Seismic Retrofitting
}

\author{
Mauro D'Apuzzo \\ Department of Civil and Mechanical Engineering DICEM, University of Cassino and Southern Lazio Cassino, \\ Italy.dapuzzo@unicas.it
}

\author{
Azzurra Evangelisti \\ Department of Civil and Mechanical Engineering DICEM, University of Cassino and Southern Lazio Cassino, \\ Italy.aevangelisti.ing@gmail.com
}

\author{
Vittorio Nicolosi \\ Department of Enterprise Engineering "Mario Lucertini", University of Rome "Tor Vergata" Rome, Italy. \\ nicolosi@uniroma2.it
}

\begin{abstract}
Alessandro Rasulo
Department of Civil and Mechanical Engineering DICEM, University of Cassino and Southern Lazio Cassino, Italy.a.rasulo@unicas.it

Daniela Santilli

Department of Civil and Mechanical Engineering DICEM, University of Cassino and Southern Lazio Cassino, Italy.daniela.santilli@unicas.it
\end{abstract}

\author{
Mirco Zullo \\ Department of Civil and Mechanical Engineering DICEM, University of Cassino and Southern Lazio Cassino, \\ Italy.mirco.zullo@libero.it
}

Prioritization methods for bridge stock seismic retrofitting underwent to a remarkable discussion among the researchers in the past thirty years. Several approaches have been proposed that can be mainly grouped according to 1) the method employed to evaluate the condition state and corresponding structural rate of failure of the specific bridge, that can be physically based or dependent on subjective judgment, and 2) the method to assess the failure cost for each bridge which is related to social cost born by the surrounding communities that can be focused on a specific bridge or on the entire transportation network operating in the area exposed to the seismic hazard.

However, the approach investigating the impact in terms of reduced efficiency of a transportation network as a result of a defined seismic input can be often extremely complex and cumbersome, as far as the computational aspect is concerned. There is therefore, a need to develop more direct and simple methods to assess the social cost related to bridge failure at the network level.

In this paper, a prioritization method based on a combined approach taking into account seismic input, specific fragility curves according to several bridge features and condition state and transportation-related failure cost is proposed The method has been applied to a case study of a local bridge stock located in central Italy to demonstrate its effectiveness.

Keywords: seismic hazard, fragility models, failure cost, transportation networks, bridge, seismic retrofitting.

\section{Background}

Nowadays, the transport system plays a decisive role in the economic and social development of every country. In order to cope with the continuous increase in traffic, both for people and goods, it is important to keep it efficient, guaranteeing maximum usability in all circumstances. In recent years, the attention of the administrations and organizations that deal with infrastructure management has focused on the maintenance of what has already been built. Given the costs to be incurred and the limited economic resources, there was the need to develop tools for the rational management of ordinary and extraordinary maintenance operations. Therefore, engineering-economic procedures are spreading to support decisionmaking of the interventions both to ensure saving of resources but, above all, to evaluate the

\section{Proceedings of the 29th European Safety and Reliability Conference. \\ Edited by Michael Beer and Enrico Zio \\ Copyright (c) 2019 European Safety and Reliability Association. \\ Published by Research Publishing, Singapore.}

ISBN: 978-981-11-2724-3; doi:10.3850/978-981-11-2724-3_0592-cd 
risk in the management of road asset. These procedures are usually implemented in integrated Asset Management System, AMS (ISO 55000, 2014). These consist of a central database, with a Geographical Information System, GIS, interface which interacts with a decision support tool. The articulation of an Asset Management System can be complex due to the interactions that exist between different assets and the relationships between the different factors and constraints. This implied a reduced diffusion of these systems at an international level.

Instead, there is consolidated literature and extensive experience in the application of systems for managing specific assets, including those relating to bridges and viaducts that will be reviewed in the followings.

\section{Bridge Management Systems}

Bridge management refers to all activities ranging from design and construction or replacement. The Organisation for Economic Cooperation and Development (OECD, 1992) defined the Bridge Management System (BMS) as an organized approach which provides to manager authorities, information for optimally planning the maintenance and control of bridges and viaducts, taking into account structural, economic and social aspects.

A survey carried out in the early 2000s (Woodward et al, 2001), as part of the Bridge Management in Europe (BRIME) project, on the state of the art of existing BMS used in Europe and abroad showed that the BMS were used in various administrative areas that have a role in the management but only in some countries they used them to define degradation models (based on analysis of the time series or on Markovian approaches).

In analogy to other road asset management systems, the BMS generally acts on two levels: i) project level which is mainly focused on the technical management of details of individual structures and ii) network level which is mainly concerned with the management of a bridge stock and where there is a greater emphasis on economic and political management issues. Between these two levels of management, there are obviously strong interactions that are mainly affected by the prioritization criteria and methods that can be employed in order to optimally allocate the limited financial resources.

As far as bridge seismic retrofitting issue is concerned, several analysis approaches have been developed (Nuti, et al., 2010; Borzi, et al.,
2015) and different methods for bridge screening and prioritization have been proposed and applied from public and private administrations (Giannini et a.,1998; Patidar et al, 2007; Davi et al, 2012; Yousefi et al, 2014), however very few of them are able to take into account socioeconomic impacts due to earthquake scenario on a specific analysis area.

\section{Objective}

The main aim of this work is to present a novel method for seismic retrofitting prioritization on a bridge stock, that is focused on the simplified approach employed to describe the transportation network and corresponding impact due to a defined seismic scenario.

The method allows a local transportation authority, to prioritize interventions even if the information on pertaining transportation road network and on foreseeable functional impacts induced by an earthquake are lacking or missing.

\section{Methodology}

The proposed prioritization method of seismic retrofitting interventions on an existing bridges stock is based on the concept of Seismic Risk, and on the evaluation of Actual Bridge Degradation State and Social Cost related to a seismic scenario. Below the definition of these parameters is presented.

\subsection{Theoretical background}

\subsubsection{Seismic Risk}

The Seismic Risk associated to a specific bridge, can be defined with the following conceptual relationship:

$$
S R=H \cdot V \cdot E
$$

Where:

$S R=$ Seismic Risk;

$H=$ Seismic Hazard;

$V=$ Vulnerability;

$E=$ Exposure .

The quantitative Seismic Risk evaluation requires a separate analysis of each of these components and their subsequent integration (see for example: Rasulo et al., 2015, Rasulo et al., 2016).

\section{Seismic Hazard}

Generally, the Seismic Hazard defines the expected seismic ground motion at a site (for example the Peak Ground Acceleration, PGA). 
According to the Probabilistic Seismic Hazard Analysis (PSHA), which explicitly takes into account the uncertainty about source location, magnitudes, attenuation to site, etc (Cornell C. A., 1968). The final outcome can be expressed either as a hazard curve (which provides the average annual probability that a ground-motion parameter can be equalized or exceeded at a site) or a map (which depicts the expected values of the ground-motion parameter over a wide area for an assigned return period).

\section{Vulnerability}

The seismic vulnerability is the predisposition of a structure to suffer a fixed level of damage, following a seismic event of a given intensity. The seismic vulnerability is generally represented by means of fragility curves, expressing the probability that a class of structures will suffer a specified damage level (light, moderate, extended or total), given a certain level of seismic input at the site (K. Pitilakis, 2014).

\section{Exposure}

The exposure can be defined as the quantification, in socio-economic terms, of the damage that a seismic event produces to a community, whose functions, under normal conditions, are exercised through the functioning of a series of material goods that are exposed to the seismic risk. In particular, the presence or absence of assets at risk and, therefore, the consequent possibility of suffering damage defines this parameter. Because of the inherent complexity of this parameter, an in-depth analysis on this issue is needed. A review of the socio-economic impacts induced by an earthquake is reported in the followings.

\subsubsection{Social Costs}

In a post-earthquake scenario, the evaluation of the exposure for critical infrastructures, such as transportation networks or lifelines, is intimately related to the assessment of the Social Costs that, in turn, are directly connected to the social and economic "Losses" that can be distinguished in:

- direct losses deriving from casualties and repair/replacement of the damaged component of the infrastructure;

- indirect losses connected with the temporary service reduction/interruption (shortmedium-term) and possible devaluation of all the aspects connected with the infrastructure (long-term).
According to recent literature (Modaressi et al., 2014) a systemic analysis of critical infrastructures (among which transportation networks are of prominent interest) have been proposed basing on different level of assessment however, it has to be reminded that this classification, that is based on the evaluation of seismic risk, has to be converted into sound criteria to prioritize maintenance or seismic retrofit interventions on a bridge stock when the budget is not unlimited and the financial constraints force the road network Manager to operate on a sample of the entire Bridge Stock on annual basis. Basing on these premises, the following analysis approaches can be proposed:

Level 0 or Base Analysis according to which, exposure is associated to road category where is located the defined bridge to the extent that major road usually accommodate higher traffic flows and therefore the exposure level is deemed to increase with the importance of the road link.

Level 1 or Volume Based Analysis where the exposure based prioritization is merely related to the value of traffic volume (usually the Annual Average Daily Traffic) travelling on the specific road where the defined bridge is located.

Level 2 or Connectivity Analysis according to which in the immediate post-earthquake scenario there will be the loss of service of some road links (as a result of bridge collapsing) impeding the access to some urban areas; in this case, prioritization is tackled basing on the amount of population that cannot be reached by emergency services;

Level 3 or Capacity Analysis that retains its original meaning insofar the Total Delay Cost for each bridge collapsing in the analysis area is evaluated and according to this parameter a prioritization can be pursued;

Level 4 or Serviceability Analysis that, as previously stated, investigates on the broader and long-term economic and supply chain related impacts on the analysis area caused by a reduced efficiency of the transportation network.

It is worth to be noticed that Level 0 and Level 1 prioritization approaches need very few data and information on road network and therefore can be easily implemented, although it has been acknowledged that they may not be enough "granular" to discriminate between different bridges and cannot accurately represent social costs in the analysis area (Small, 2000). 
Level 2 analysis plays a critical role in the management of the emergency services in the immediate post-earthquake scenario. However, on one hand, it requires a mathematical formalization that even for very small networks implies a cumbersome computational effort (Sanchez-Silva et al., 2013) whereas, on the other, as a matter of fact, in industrialized countries, connectivity level is often characterized by a remarkable redundancy thus implying a lower effect on overall social costs.

Level 4 analysis requires a huge amount of data on land use and socio-economic information and also several additional skills on economic analysis that can be hardly retrieved in Local Road Agencies (Modaressi et al., 2014). Level 3 appears, so far, an affordable compromise between the need of a sounder evaluation of Socio-economic Costs related to conventional maintenance or seismic retrofitting of a bridge stock and the quality of information available for Local Road Authorities.

However, this kind of analysis requires, at least, the knowledge of the entire Origin-Destination $(\mathrm{O} / \mathrm{D})$ trip matrix of the analysis area and, more generally, the development and implementation of a transportation demand prediction model or traffic forecasting model.

A traffic forecasting model (formerly known as four-step travel demand model) can be formally expressed by the following equation (Cascetta, 2009):

$d_{o d}^{i}(s, h, m, k)=d_{o}^{i}(s h) \cdot p^{i}(d / o s h) \cdot$

$p^{i}(m / o s h d) \cdot p^{i}(k / o s h d m)$

where:

$d_{\text {od }}^{i}(s, h, m, k)$ is the average number of trips carried out by class user i (depending on the socio-economic role of the user) starting from origin traffic zone $o$, and terminating in the destination traffic zone $d$, for a specific purpose $s$, within the time period $h$, using the transport mode $m$, and choosing the trip path $k$;

$d_{o}{ }_{o}(s h)$ is the average number of class user $i$ who perform a trip from origin zone $o$, for purpose $s$, within the time period $h$ (better known as the traffic generation sub-model);

$p^{i}(d / o s h)$ is the fraction of the aforementioned users who terminate the trip in the destination zone $d$ (known as the traffic distribution submodel); $p^{i}(m / o s h d)$ is the fraction of the aforementioned users who choose the transport mode $m$ (known as the traffic mode-choice sub-model);

$p^{i}(k / o s h d m)$ is the fraction of the aforementioned users who choose the trip path $k$ (this is commonly known as the traffic assignment or path-choice sub-model).

Once that the mobility scenario has been evaluated, the Generalized Transport Cost, GTC, for the analysis area can be assessed. Among the different terms contributing to the GTC, the travel time is the most significant. If therefore the hourly cost for each trip can be defined according to the specific trip purpose, $s, G T C$ can be calculated for the analysis area and the Total Delay Cost, TDC, can be expressed by means of the following equation:

$T D C=G T C_{\text {post }}-G T C_{\text {pre }}$

where:

$G T C_{\text {post }}$ is the Generalized Transport Cost, for the analysis area in the post-earthquake scenario evaluated on daily basis;

$G T C_{\text {pre }}$ is the Generalized Transport Cost, for the analysis area in the pre-earthquake scenario, evaluated on the daily basis.

If the Social Costs have to be embedded in the prioritization scheme for seismic retrofitting or conventional maintenance of a bridge stock, the exposure term can be therefore related to the $T D C$ following the collapse and the related road disruption of each singularly examined bridge belonging to the stock.

The overall Social Cost will be therefore obtained by multiplying the $T D C$ by the overall amount of days necessary to restore the original bridge serviceability conditions.

\subsection{Prioritization Index Definition}

Following these premises, two different approaches will be presented for the application of the proposed prioritization method of seismic retrofitting interventions on an existing bridges stock. Both are based on a linear combination of three indices, and in particular:

$$
\begin{aligned}
& P I_{i}=V I_{i} \cdot E I_{i} \cdot D I_{i} \\
& S P I_{i}=V I_{i} \cdot S E I_{i} \cdot D I_{i}
\end{aligned}
$$

where: 
$P I_{i}=$ Prioritization Index for seismic retrofitting of the $i$-th bridge;

$S P I_{i}=$ Simplified Prioritization Index of the $i$-th bridge;

$V I_{i}=$ Vulnerability Index of the $i$-th bridge;

$E I_{i}=$ Exposure Index of the $i$-th bridge, evaluated basing on Social Costs;

$D I_{i}=$ Degradation State Index of the $i$-th bridge, for seismic-retrofitting;

$S E I_{i}=$ Simplified Exposure Index of the $i$-th bridge.

The evaluation of these parameters is explained below.

\subsubsection{Vulnerability Index definition}

The $V I_{i}$, referred to the $i$-th bridge, is calculated with the Eq. 6:

$$
V I_{i}=\frac{V c_{i}}{V c_{\max }}
$$

where:

$V I i=$ Vulnerability Index of the i-th bridge;

$V c_{i}=$ Vulnerability Curve Index of the i-th bridge;

$V c_{\max }=$ Maximum Vulnerability Curve Index of the entire bridges stock.

In particular the Vulnerability Curve Index is calculated integrating the Vulnerability Curve, which is defined as the convolution between the Seismic Hazard Curve and the Fragility Curve.

\subsubsection{Bridge Degradation State Index definition}

The evaluation of the Degradation State Index, for seismic retrofitting, is based on the knowledge of the actual deterioration state of each single bridge (and of each of its composing element as abutment, pile, span, ...) belonging to the entire stock. Generally, this data can be acquired during the Bridge Safety Inspections and different National and International techniques have been proposed (AASHTO, 2013; Chase et al., 2016; etc).

The $D I$, referred to the $i$-th bridge, is calculated with the Eq. 7:

$$
D I_{i}=\frac{T D_{i}}{T D_{\max }}
$$

Where:

$D I_{i}=$ Degradation State Index of the $i$-th bridge, for seismic retrofitting;
$T D_{i}=$ Total Degradation State value of the $i$-th bridge;

$T D_{\max }=$ Maximum Total Degradation State value computed on the entire bridges stock.

In particular the Total Degradation State value is calculated with the Eq. 8:

$$
T D_{i}=\frac{\sum_{j=1}^{m} W_{e_{j}} \cdot E D_{j} \cdot C_{a_{j}}}{n_{s}}
$$

where:

$T D_{i}=$ Total Degradation State value of the $i$-th bridge;

$n_{s}=$ number of span composing the $i$-th bridge;

$m=$ number of element composing the $i$-th bridge;

$E D_{j}=$ Degradation State of the $j$-th bridge's element. This value can be evaluated by expert inspectors crew;

$C a_{j}=$ Coefficient depending on the age of the $j$-th bridge's element;

$W e_{j}=$ Weight depending on the j-th element type (as abutment, pile, span, ...) and on intervention type.

As far as this latter term is concerned, it is worth to be noticed that the Weight value is dependent on the intervention type since different level and type of degradations on several bridge elements may have a different impact on bridge serviceability if a conventional maintenance or a seismic retrofitting intervention has to be evaluated.

\subsubsection{Exposure Index definition}

For the bridges' exposure evaluation two different approaches have been proposed: the first one, defined "Conventional", is based on the Social Costs estimation and the last one, defined "Simplified", is based on the Vehicular Traffic evaluation.

In particular, the Eq. 9 and the Eq. 10 can be used for the evaluation of the Conventional and Simplified approaches, respectively:

$$
\begin{aligned}
E I_{i} & =\frac{S C_{i}}{S C_{\text {max }}} \\
S E I_{i} & =\frac{A D T_{i}}{A D T_{\max }}
\end{aligned}
$$

Where:

$E I_{i}=$ Exposure Index of the $i$-th bridge;

$S E I_{i}=$ Simplified Exposure Index of the $i$-th bridge; 
$S C_{i}=$ Social Cost of the $i$-th bridge;

$S C_{\max }=$ Maximum Social Cost evaluated on the entire bridge stock;

$A D T i=$ Bidirectional Average Daily Traffic travelling on the $i$-th bridge;

$A D T_{\max }=$ Maximum bidirectional Average Daily Traffic evaluated on the entire bridge stock.

\section{Case Study}

Both Conventional and Simplified approaches have been applied on a sample of a bridge stock managed by a Road Agency in central Italy. An overall number of 37 road bridges have been evaluated.

Visual inspections have been performed for each bridge and the Total Degradation State value of the $i$-th bridge, for seismic retrofitting, has been evaluated.

For the Vulnerability Index evaluation, for each bridge, the Seismic Hazard Curve has been evaluated. In particular, a period of 1 second and 50 -year return period have been selected for the application (see Fig.1). Conversely a unique Fragility Curve has been selected for the entire bridges' stock (Azevedo, 2010).

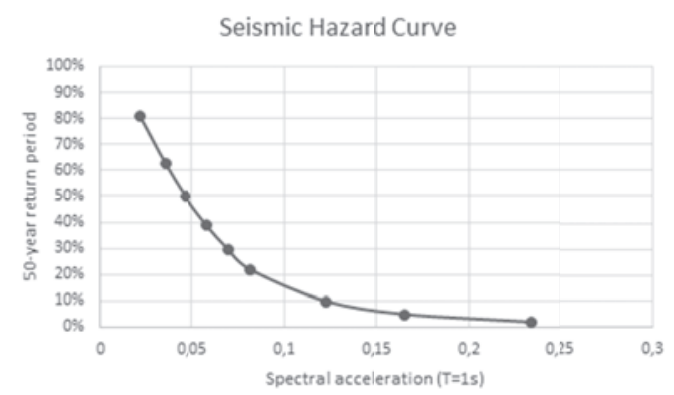

Fig. 1. Seismic Hazard Curve for i-th bridge.

The multiplication of the two curves produces the Vulnerability curve, represented in the Fig. 2.

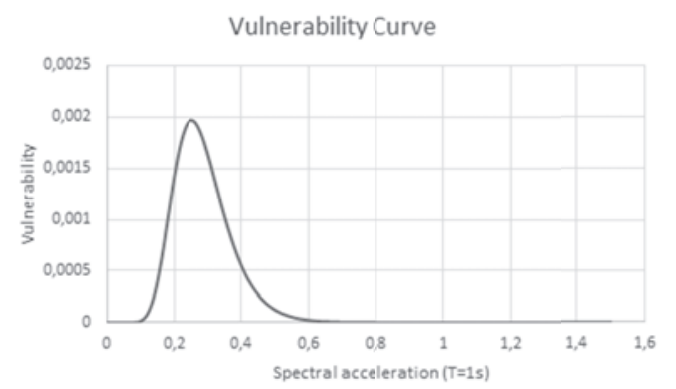

Fig. 3. Traffic Zones and internal and external Centroids in the analysis area.

Three realistic alternative itineraries, for each couple of internal centroids have been identified, including local roads with bridges, if possible. The selected road network is represented in the Fig.4.

Fig. 2. Vulnerability Curve for i-th bridge. 


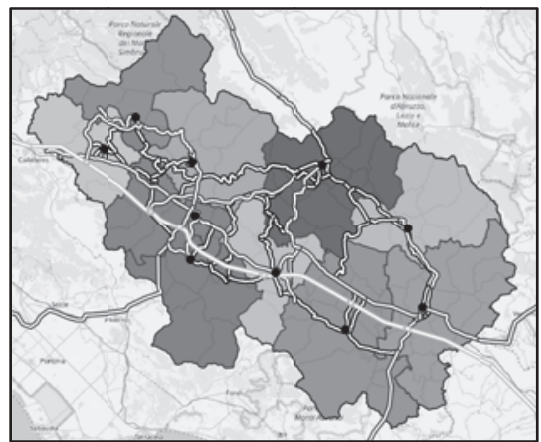

Fig. 4. Road network identified in the analysis area.

The collapse of one bridge at a time has been hypothesized and, for each scenario, the previous traffic hourly volume values has been reassigned according to a "all-or-nothing" conventional rule. The Social Cost, $S C$, can then be evaluated by multiplying the Generalized Travel Costs in the ex-ante and in the ex-post earthquake scenarios provided by the transport forecasting model by the hourly travel cost that has been estimated in $12 € / \mathrm{h}$ and $45 € / \mathrm{h}$ for light and heavy vehicle respectively. Finally, following the evaluation of the Total Delay Cost, $T D C$, as difference of $G T C$ in the two scenarios, the direct Social Cost, for each collapsed bridge, has been computed by multiplying the TDC by the number of days needed to restore initial bridge conditions.

The results for the seismic retrofitting, for both Conventional $(P I)$ and Simplified (SEI) approaches and corresponding Pearson' coefficient, have been summarized in the Fig.5.

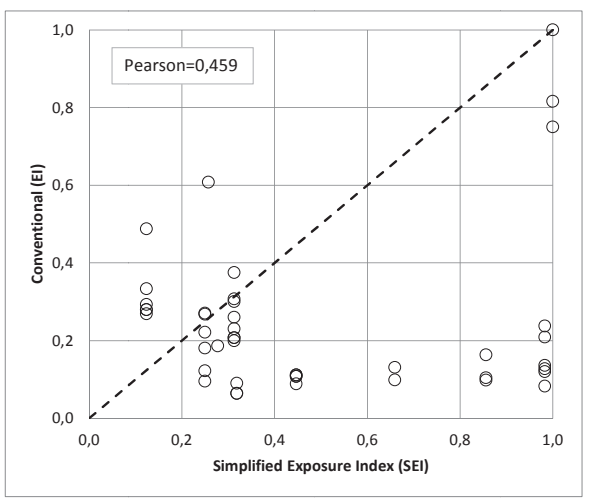

Fig. 5. Comparison between Conventional (EI) and Simplified Exposure Index (SEI) prioritization methods for seismic retrofitting.

As it can be easily observed by the figure, the Simplified Exposure Index (Eq. 10), was not efficient in describing prioritization criteria based on social cost. In order to gain a better estimate of the Exposure Index, the following relationship has been propiosed:

$$
S S C_{i}=k_{1} \cdot S E i_{i}^{k_{2}} \cdot L_{B i}^{k_{3}} \cdot \Delta L d_{i}^{k_{4}}
$$

where:

\section{$S S C_{i}=$ Simplified Social Cost Index for the $i$-th} bridge;

$S E I_{i}=$ Simplified Exposure Index, that, as previously defined is the ratio between the Average Daily Traffic traveling on the collapsed $i$-th bridge and the maximum value of the $A D T$;

$L_{B i}=$ ratio between the length of the collapsed $i$ th bridge and the maximum value of the bridge length derived from the entire bridge stock;

$L_{d i}=$ ration between the incremental length of the detour for the collapsed $i$-th bridge;

$k_{1}=3,032 ; k_{2}=0,626 ; k_{3}=0,208 ; k_{4}=0,858$ are calibration constants.

A comparison between the prioritization index with this latter approach and resulting Pearson' coefficient, is reported in Fig. 6.

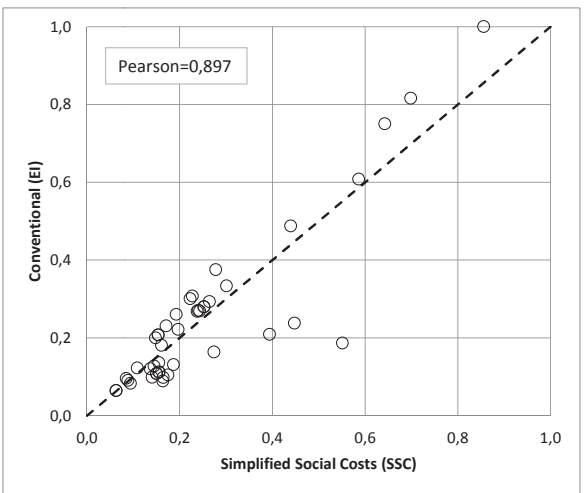

Fig. 6. Results of the Conventional (EI) and Simplified Social Cost (SSC) prioritization methodls for seismic retrofitting.

As it can be seen from the figure, result with the Simplified Social Cost Index (Eq. 11) greatly improved, since a better agreement with the social cost approach is obtained.

\section{Conclusions}

A novel method for seismic retrofitting prioritization on a bridge stock, based on the simplified approach for describing the transportation network has been developed. The method provides a prioritization classification of the interventions even if the information on pertaining transportation road network and on possible functional impacts due to a seismic 
event, are lacking or missing. As far as the impact on intervention's policies are concerned, degradation state and exposure index related to social (delay) cost appear the most prominent.

A comparison between the Conventional approach, based on the evaluation of the Social Cost and the Simplified approach, based on the estimate of the Simplified Social Cost Index has been presented and preliminary results show a fairly good agreement between the prioritization classification for the retrofitting intervention planning.

\section{References}

AASHTO (2013) "Manual for Bridge Evaluation", American Association of State Highway and Transportation Officials. ISBN: 978-1-56051-557-9.

Azevedo J, Guerreiro L, Bento R, Lopes M, Proença J (2010) Seismic vulnerability of lifelines in the greater Lisbon area. Bull Earthq Eng 8(1):157-180.

Borzi B., Ceresa P., Franchin P., Noto F., Calvi G.M., Pinto P.E. (2015). Seismic vulnerability of the Italian roadway bridge stock. Earthquake Spectra, 31(4), 2137-2161.

Cascetta, E., (2009) "Transportation Systems Analysis. Models and Applications." Second Edition, Springer Verlag, DOI 10.1007/9780-387-75857-2, pp. 1-752.

Chase, S.B., Adu-Gyamfi, Y., Aktan, A.E., and Minaie, E. 2016. "Synthesis of National and International Methodologies Used for Bridge Health Indices" PUBLICATION NO. FHWA-HRT-15-081.

Cornell C. A., 1968. Engineering seismic risk analysis, Bull. Seism. Soc. Am., 58, 15831606.

Davi D., Criado D., Thibault C., Bertrand E., Vivier A., Marchand P. \& Charles P. (2012), "A Global Methodology for Seismic Vulnerability Assessment and Retrofit of Existing Bridges adapted to the French Context". Proceedings of the 15th World Conference on Earthquake Engineering 2012 - Lisbon, Portugal 24-28 September 2012. Volume 4. ISBN: 978-1-63439-651-6 pp. 2520-2527.

Giannini R., Donferri M., Nuti C., Pinto P.E. (1998), Analisi di Rischio Sismico dei Ponti della Rete della Società Autostrade, AUTOSTRADE.

ISO 55000 - Asset management -- Management systems - Requirements. Standard for Asset Management, 2014.

Modaressi H., Desramaut N., Gehl P. (2014) Specification of the Vulnerability of Physical Systems. Chapter 5 in: SYNER-G: Systemic Seismic Vulnerability and Risk Assessment of Complex Urban, Utility, Lifeline Systems and Critical Facilities. Methodology and Applications. Geotechnical, Geological and Earthquake Engineering, vol 31. Springer, Dordrecht. Pp 131-184.

Nuti C., Rasulo A., Vanzi I.: Seismic safety of network structures and infrastructures. Structure \& Infrastructure Engineering: Maintenance, Management, Life-Cycl 6(12), 95-110 (2010).

OECD Organisation for Economic Cooperation and Development. 1992. Bridge Management, Road Transport Research. Paris.

Patidar V., Labi S., Sinha K., Thompson P., 2007 "Multi-Objective Optimization for Bridge Management Systems" NCHRP Report 590, DOI 10.17226/23147, pp. 1-30.

Pitilakis K., Franchin P., Khazai B., Wenzel H. (2014) SYNER-G: Systemic Seismic Vulnerability and Risk Assessment of Complex Urban, Utility, Lifeline Systems and Critical Facilities. Methodology and Applications. Geotechnical, Geological and Earthquake Engineering, vol 31. Springer, Dordrecht.

Rasulo A., Testa C., Borzi B. (2015) Seismic Risk Analysis at Urban Scale in Italy. In: Gervasi O. et al. (eds) Computational Science and Its Applications -- ICCSA 2015. ICCSA 2015. Lecture Notes in Computer Science, vol 9157. Springer, Cham.

Rasulo A., Fortuna M.A., Borzi B. (2016) A Seismic Risk Model for Italy. In: Gervasi O. et al. (eds) Computational Science and Its Applications -- ICCSA 2016. ICCSA 2016. Lecture Notes in Computer Science, vol 9788. Springer, Cham.

Sanchez-Silva M. and Gomez C., (2013). "Risk Assessment and management of civil infrastructure networks. A system approach" Chapter 17 in Handbook of seismic risk analysis, Woodhead Published Limited.

Small, Edgar. (2000). Examination of Alternative Strategies for Integration of Seismic Risk Considerations in Bridge Management Systems. TRB Transportation Research Circular 498.

Woodward R J et al., 2001. BRIME Bride Management in Europe - FINAL REPORT. Contract No.: RO-97-SC.2220. https://trimis.ec.europa.eu/sites/default/files/p roject/documents/brimerep.pdf

Yousefi, Mohd Sanusi S. Ahamad \& Taksiah A. Majid (2014). Application of TOPSIS method in prioritization of highway bridges for seismic retrofitting, Engineering Structures and Technologies, 6:3, 114-123, DOI: $10.3846 / 2029882 X .2014 .980853$. 